\author{
제약회사의 내부마케팅활동과 직무만족, 조직몰입, 이직의도와의 관계 \\ -제약영업사원을 중심으로- \\ 차재빈, 류가연 \\ 경희대학교 일반대학원 경영학과
}

\title{
The Relationship among Internal Marketing Activities, Job Satisfaction, Organizational Commitment, and Turnover Intention in Pharmaceutical
} Companies -Focusing on Pharmaceutical Salespeople-

\author{
Jae-Bin Cha, Ga-Yeon RYU \\ Department of Business Administration, Graduate School, Kyunghee University
}

\begin{abstract}
$<$ Abstract $>$
The initial approach to this study is to focus on pharmaceutical companies' internal marketing activities for organizational diagnosis.

By analysing the influence of internal marketing elements on the job satisfaction, organizational commitment, and turnover intention of pharmaceutical salespeople, this study aims at coming up with ways to strengthen the sales capacity and competitive edge of pharmaceutical companies through the salespeople's satisfaction. For 32 days between November 10th and December 12th of 2012, a total of 210 copies of questionnaires were given to the respondents and 203 of them except 7 with insufficient answers were used for the final analysis.

The analysis result showed that internal communication, delegation of authority, and reward system among the elements of internal marketing activity had a positive influence on the workers' job satisfaction. The internal marketing activity elements did not influence the respondents' organizational commitment. Job satisfaction had a positive influence on their organizational commitment, while it had a negative influence of turnover intention.

The conclusion section encapsulated the results of empirical analysis and proposed practical lessons regarding pharmaceutical companies' internal marketing.
\end{abstract}

Key Words : Internal Marketing, Job Satisfaction, Organizational Commitment, Turnover Intention, Pharmaceutical Salespeople

‡Corresponding author(rgy415@hanmail.net) 


\section{I . 서론}

신약을 개발하고 생산하는 제약 산업은 생명을 구하는 의료측면뿐만 아니라 무한한 성장잠재력과 지대한 영향력으로 21세기를 주도할 선도 산업으 로 주목을 받고 있다. 부족한 부존자원에 비해 두 뇌인력이 풍부한 우리나라 실정에서 다른 산업보 다 부가가치가 월등한 제약 산업은 선진국으로 들 어서는 지름길이 될 수 있다. 제약 산업에서 경쟁 력을 갖춘 인적자원은 기업의 경쟁우위를 창출하 는 원동력이며, 조직의 지속적 생존과 발전을 위한 전략적 요소이자 핵심자산이라는 공감대가 형성되 어, 기업은 인적자원의 능력개발과 경영전략을 지 원하기 위한 핵심요소로 인식하여 투자를 강화하 고 있다. 그 중에서도 기업의 영업사원 또는 판매 원의 역할은 기업의 성과에 직접적으로 영향을 미 칠 뿐만 아니라, 장기적으로 기업과 고객과의 관계 에도 중요한 영향을 미치는 것으로 나타나고 있다 [1]. 그들은 고객과의 접점에서 상호작용을 하면서 고객과의 정보교환의 주요 원천 구실을 하며 고객 과의 관계를 형성하고 지속적인 관계를 유지하는 데 중요한 역할을 담당한다[2]. 특히, 기업의 매출 근간을 영업조직에 두고 있는 기업에서는 영업사 원의 이직은 매출감소 뿐만 아니라 고객단절로 인 한 시장위축까지 이어지게 된다[3]. 이러한 중요성 에 기인하여 영업사원의 직무태도와 행동 간의 관 계를 다루는 많은 연구들이 이루어져 왔다. 영업사 원은 기업을 대표하는 역할을 담당하기도 하고 고 객의 욕구를 파악하여 이에 대응하는 역할을 수행 하고 있기 때문에 이들의 이직은 기업의 성과에 영향을 미치게 된다. 현장 접점에서 여러 고객을 관리해 오던 영업사원이 이직하게 되면, 기업과 고 객의 관계는 상당한 변화가 일어나게 되고, 장기적 으로 고객은 자신과 직접 관계를 맺고 있던 담당 자의 이직으로 해당 기업과의 관계를 재검토하는 계기가 되기도 한다[4]. 이와 같은 결과는 기업의
성과에 직접적으로 영향을 미칠 뿐만 아니라 고객 과의 지속적이고 안정적인 관계유지가 어려워지게 되어 매출감소, 시장약화 등과 같이 기업성과에 부 정적인 영향을 받게 된다.

국내 의료분야나 마케팅 분야에서는 영업사원과 관련된 연구 중 제약영업사원과 관련된 연구들이 많이 이루어지지 않았다. 일반적으로 영업사원의 이직행동을 연구주제로 한 국내연구들은 몇몇 연 구를 제외하면 거의 없다고 볼 수 있다. 이직행동 을 주제로 한 대표적인 국내연구들을 살펴보면, 영 업사원 이직의도에 영향을 미치는 선행변수에 관 한 연구[5], 영업사원 이직의도에 있어 대안 매력 도와 조직몰입이 갖는 매개적 역할을 다룬 연구[6] 등이 있다. 또한 이러한 연구들이 공통적으로 지니 고 있는 특성은 궁극적인 종속변수로서 영업사원 들의 이직행동 또는 이직의도에 관심을 갖고 있다 는 점이다. 그러나 주요 변수로서 각 영업사원이 지각하고 있는 역할에 대한 스트레스 요인과 직무 성과 및 조직몰입과 같은 개인이 조직에 지각하고 있는 태도변수들만을 고려했다는 한계점을 지니고 있다.

기업의 경영에서 가장 중요한 것은 고객이지만 그 고객과의 관계를 형성하고 유지하는 것은 종사 원이며, 그들로 하여금 고객을 만족시킬 수 있게 하기 위해서는 종사원의 만족이 선행되어야 한다. 또한, 고객의 다양한 요구를 파악하고 해결하기 위 해서는 종사원들의 역량 향상이 요구된다. 이는 보 다 발전된 형태의 서비스를 고객에게 제공하게 되 고, 이러한 활동은 고객의 만족을 향상 시킬 수 있 기 때문이다. 이러한 점에서 제약영업사원은 회사 의 직접마케팅을 위해 매우 중요한 역할을 수행한 다. 즉, 회사의 제품을 판매하기 위해 고객과 일대 일 커뮤니케이션을 하면서 회사의 이미지에 많은 영향을 주고, 고객을 향한 사후서비스를 제공함으 로써 재 구매를 유도한다. 물론 각종 광고와 프로 모션행사 등과 같은 직접마케팅을 통하여 판매성 
과를 이루기도 한다. 그러나 영업사원의 일대일 마 케팅은 상품에 대한 고객인식과 구매의지여부, 궁 금증을 현장에서 파악할 수 있으며 즉각적인 피드 백과 소통이 가능하다. 고객접점의 정보를 통해 시 장에서의 제품인식수준과 현황을 객관적으로 파악 하여 보다 나은 개선을 위한 아이디어를 제공받을 수 있다는 점에서 제약영업사원의 역할은 다양하 다고 볼 수 있다. 따라서 제약회사에서는 내부마케 팅활동을 통하여 다양한 역할을 하고 있는 영업사 원을 내부고객으로 인식하고 그들의 다양한 욕구 를 충족시켜 회사의 매출성과에 기여할 수 있는 방안을 강구할 필요가 있다.

\section{2. 연구의 목적}

본 연구에서는 일차적으로 조직 진단 차원에서 의 내부마케팅활동에 초점을 두고 접근하고자 한 다. 내부마케팅은 영업사원을 내부 고객으로 간주 하고, 영업사원의 업무수행 능력을 제품으로 보는 개념으로 내부 고객을 만족시켜 내부 서비스품질 을 향상시키고 외부고객을 만족시킨다는 이론이다. 조직의 정확한 내적환경 및 상황분석이 되지 않은 상태에서 효과적인 외부마케팅 전략을 수립한다는 것은 불가능하다. 제약회사는 고객에게 제공하는 서비스품질의 향상 및 고객만족을 창출할 수 있는
영업사원에게 필요한 전략적인 도구로 내부마케팅 을 연구해야할 필요성이 있다. 특히 내부마케팅의 요인들이 영업사원의 직무만족, 조직몰입 및 이직 의도에 어떤 영향을 주는가를 분석함으로써 제약 회사 영업사원들의 만족을 통한 영업력 향상과 경 쟁우의를 얻고자 하는데 연구의 의의를 둔다.

본 논문의 연구목적을 보다 구체적으로 제시하 면 다음과 같다. 첫째, 제약회사의 내부마케팅활동 요인과 직무만족과의 인과적 관계를 알아본다. 둘 째, 제약회사의 내부마케팅활동 요인과 조직몰입과 의 인과적 관계를 알아본다. 셋째, 제약회사의 내 부마케팅활동 요인과 이직의도와의 인과적 관계를 알아본다. 넷째, 직무만족과 조직몰입, 이직의도의 인과적 관계를 알아본다.

\section{ㅍ. 연구방법}

1. 연구모형 및 가설설정

문헌고찰을 통해 도출된 연구들을 종합하여 내 부마케팅활동과 직무만족, 조직몰입, 이직의도의 관련성이 있다고 판단되어 <Figure $1>$ 과 같은 연 구모형을 설정하였다. 그리고 선행연구들을 기초로 하여 다음과 같은 가설을 설정하였다.

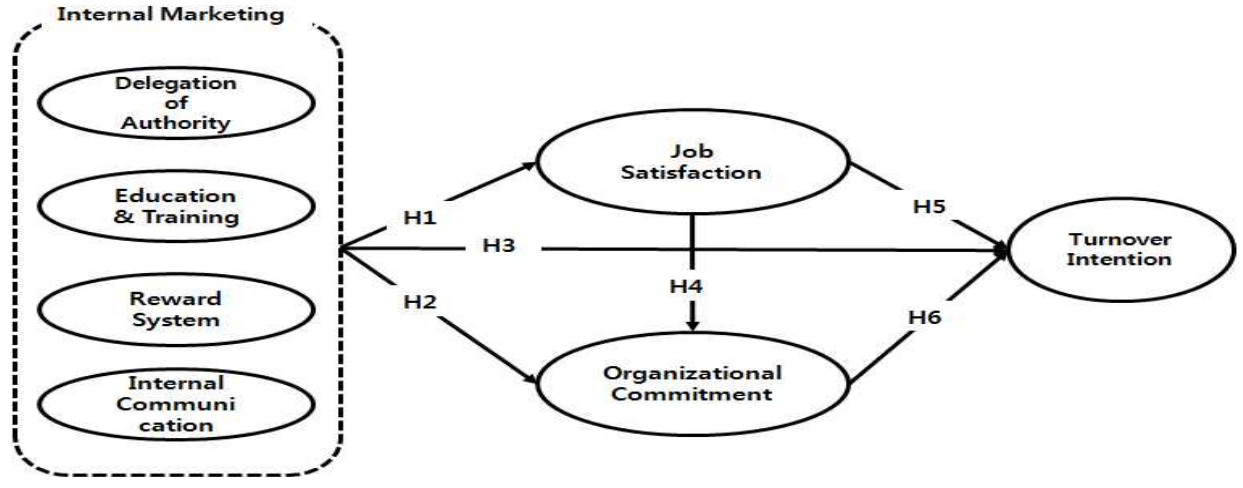

<Figure 1> Research Model 
<가설 1> 제약회사의 내부마케팅활동은 직무만 족에 정 $(+)$ 의 영향을 미칠 것이다.

가설1_1 내부마케팅활동 중 권한위임은 직무만 족에 정 $(+)$ 의 영향을 미칠 것이다.

가설1_2 내부마케팅활동 중 교육훈련은 직무만 족에 정 $(+)$ 의 영향을 미칠 것이다.

가설1_3 내부마케팅활동 중 보상제도는 직무만 족에 정 $(+)$ 의 영향을 미칠 것이다.

가설1_4 내부마케팅활동 중 내부커뮤니케이션은 직무만족에 정 $(+)$ 의 영향을 미칠 것이다.

<가설 2> 제약회사의 내부마케팅활동은 직무몰 입에 정(+)의 영향을 미칠 것이다.

가설2_1 내부마케팅활동 중 권한위임은 직무만 족에 정 $(+)$ 의 영향을 미칠 것이다.

가설2_2 내부마케팅활동 중 교육훈련은 직무만 족에 정(+)의 영향을 미칠 것이다.

가설2_3 내부마케팅활동 중 보상제도는 직무만 족에 정 $(+)$ 의 영향을 미칠 것이다.

가설2_4 내부마케팅활동 중 내부커뮤니케이션은 직무만족에 정 $(+)$ 의 영향을 미칠 것이다.

<가설 3> 제약회사의 내부마케팅활동은 이직의 도에 부(-)의 영향을 미칠 것이다.

가설3_1 내부마케팅활동 중 권한위임은 이직의 도에 부(-)의 영향을 미칠 것이다.

가설3_2 내부마케팅활동 중 교육훈련은 이직의 도에 부(-)의 영향을 미칠 것이다.

가설3_3 내부마케팅활동 중 보상제도는 이직의 도에 부(-)의 영향을 미칠 것이다.

가설3_4 내부마케팅활동 중 내부커뮤니케이션은 이직의도에 부(-)의 영향을 미칠 것이다.

<가설 4> 직무만족은 조직몰입에 정 $(+)$ 의 영향 을 미칠 것이다.
<가설 5> 직무만족은 이직의도에 부(-)의 영향 을 미칠 것이다.

<가설 6> 조직몰입은 이직의도에 부(-)의 영향 을 미칠 것이다.

2. 조사대상 및 자료수집

연구모형을 검증하기 위해 국내·외 제약회사에 근무하고 있는 영업사원들을 대상으로 설문조사를 실시하였다. 설문조사는 2012년 11월 10일부터 2012년 12월 12일까지 32일간 총 210부를 배포하 여 불성실한 설문응답 7 부를 제외한 203 부를 최종 분석에 사용하였다.

\section{3. 조사도구}

본 연구에 이용된 모든 측정항목들은 " 1 점= 전 혀 그렇지 않다"에서 "7점 = 매우 그렇다"의 7점 척도로 측정하였으며 설문항목은 선행연구를 바탕 으로 본 연구실정에 맞게 수정 또는 응용하였다. 내부마케팅활동 요인은 권한위임, 교육훈련, 보상 제도, 내부커뮤니케이션의 4 가지 요소로 정의하였 다[7]. 권한위임은 기업이 직원에게 업무와 관련된 활동에 대하여 자율적 의사결정을 할 수 있는 자 유재량권을 제공하는 것이다. 따라서 권한위임은 업무 수행 시 발생하는 다양한 문제 해결을 통해 고객서비스를 향상시키는 중요한 요소가 된다. 교 육훈련은 마케팅에 대한 직원의 태도를 변화시키 는 역할을 하기 때문에 내부마케팅을 실행시키기 위한 중요한 구성요소가 된다. Jung[8]은 인적자원 관리의 계획과 수행에서 보상제도는 조직의 시장 지향성을 증진시킬 수 있는 직접적이며 적극적인 방법이 될 수 있다고 하였다. 또한 보상제도를 통 하여 시장지향성과 일치하는 새로운 행동과 태도 를 수용하고자 하는 동기를 종업원들에게 유발 시 
킬 수 있게 된다[9]. 커뮤니케이션은 직원과 기업 이 공통적으로 조직의 가치와 목적을 인식할 수 있도록 정보를 공유하여 직원이 조직의 새로운 정 책과 철학을 공유하도록 설득하는 수단이 되기도 한다[10]. 또한, 기업과 직원간의 커뮤니케이션에 의해 지원을 증대시킬 수 있고 직원에게 피드백을 제공하여 업무에 대한 만족도를 제고시킬 수 있다 고 제시하였다[11]. 직무만족은 '개인의 직무 또는 직무경험으로부터 발생하는 전반적인 유쾌함 또는 긍정적 감정상태'를 말한다[12]. 선행연구에서 직무 만족을 측정하는데 이용한 문항 중 4 개 문항을 이 용하여 측정하였다[13]. 조직몰입은 자신이 속한 직업에 대해 몰입, 일체감, 애착심을 나타내며 조 직이 추구하는 목표나 가치에 대한 강한 신뢰와 수용, 조직을 위해 애쓰려는 의사, 조직의 구성원 으로 남아 있으려는 강한 의지를 의미한다[14]. 본 연구에서는 조직에 대하여 느끼는 심리적인 애착 을 말하는 것으로 정의하고, 척도를 변환하여 4 개 문항을 본 연구실정에 맞게 수정 또는 응용하였다. 이직의도는 조직 내 종사원이 조직의 구성원이기 를 포기하고 현 직장을 떠나려는 의도로 정의된다 [15]. 이직의도는 선행연구에서 사용된 측정항목 중 5개 문항을 수정 또는 응용하였다.

\section{4. 분석방법}

수집된 자료를 분석하기 위하여 IBM PASW20.0 통계패키지를 활용하였다. 먼저 응답자의 일반적 특성을 파악하기 위하여 빈도분석을 하였다. 그리 고 각 문항들이 이론변수들을 제대로 측정하였는 가를 알아보기 위하여 탐색적 요인분석을 실시하 고, 연구도구의 신뢰도 및 타당도를 분석하였다. 다음으로 $\mathrm{AMOS} 20.0$ 을 이용하여 확인적 요인분석 을 실시하고, 평가도구의 타당도를 검증하였다. 마 지막으로 모형의 적합성과 각 요인들 간의 인과관 계를 분석하기 위하여 구조방정식 모형분석을 실
시하였다.

\section{III. 연구결과}

\section{1. 연구대상의 일반적 특성}

분석에 포함된 응답자들의 일반적 특성들을 살 펴보면, 성별의 구성은 남성이 $95.1 \%(193$ 명), 여성 이 $4.9 \%(10$ 명)로 여성보다 남성의 비율이 높았으며 연령은 20-29세가 $\quad 17.2 \%(35$ 명), 30-39세가 $73.4 \%(149$ 명), 40-49세가 9.4\%(19명)로 설문 응답자 의 대부분은 30-39세가 가장 많았다. 월 급여는 251-300만원이 $47.3 \%$ (96명)으로 가장 많은 비율을 차지하였으며 301-350만원 20.2\%(41명), 201-250만 원 $17.2 \%$ (35명)순이었다. 다음으로 근속년수는 1 년 미만 4.4\%(9명), 1-3년 미만 28.1\%(57명), 3-10년 미 만 51.2\%(104명), 10-15년 미만 13.3\%(27명), 15-20 년 미만 2.5\%(5명), 20년 이상 0.5\%(1명)로 3-10년 미만이 가장 많았다. 직위는 사원이 $28.6 \%(58$ 명), 주임 $18.7 \%(38$ 명), 대리 $18.7 \%(38$ 명), 과장 $21.2 \%(43$ 명), 차장 $9.4 \%(19$ 명), 부장 $3.4 \%(7$ 명)로 나 타났다. 직책은 팀원 $88.7 \%(180$ 명), 팀장 $11.3 \%(23$ 명)으로 팀원의 비율이 다소 높았으며, 영업사원이 담당하는 병원규모는 의원급(30bed미만) $17.7 \%$ (36 명), 준병원급(30 100bed미만) $43.3 \%$ (88명), 종합병 원 및 대학병원급(100bed이상) $38.9 \%$ (79명)로 분포 되어 있었다. 근무하고 있는 제약회사로는 국내제 약회사가 $\quad 93.1 \%(189$ 명), 외국계 제약회사가 $6.9 \%(14$ 명)로 국내제약회사의 비중이 대부분 차지 하였다<Table 1>. 
$<$ Table $1>$ General characteristics of study subjects

\begin{tabular}{|c|c|c|c|}
\hline & Variables & Frequency & Percent(\%) \\
\hline \multirow{2}{*}{ Sex } & male & 193 & 95.1 \\
\hline & female & 10 & 4.9 \\
\hline \multirow{3}{*}{ Age } & $20-29$ & 35 & 17.2 \\
\hline & $30-39$ & 149 & 73.4 \\
\hline & $40-49$ & 19 & 9.4 \\
\hline \multirow{6}{*}{$\begin{array}{l}\text { Salary per month } \\
(10,000 \text { won })\end{array}$} & $<200$ & 2 & 1.0 \\
\hline & $201-250$ & 35 & 17.2 \\
\hline & $251-300$ & 96 & 47.3 \\
\hline & $301-350$ & 41 & 20.2 \\
\hline & $351-400$ & 19 & 9.4 \\
\hline & $400<=$ & 10 & 4.9 \\
\hline \multirow{6}{*}{$\begin{array}{l}\text { Tenure } \\
\text { (year) }\end{array}$} & $<=1$ & 9 & 4.4 \\
\hline & $1-3$ & 57 & 28.1 \\
\hline & $3-10$ & 104 & 51.2 \\
\hline & $10-15$ & 27 & 13.3 \\
\hline & $15-20$ & 5 & 2.5 \\
\hline & $20<=$ & 1 & 0.5 \\
\hline \multirow{6}{*}{ Status } & employee & 58 & 28.6 \\
\hline & chief & 38 & 18.7 \\
\hline & deputy & 38 & 18.7 \\
\hline & section chief & 43 & 21.2 \\
\hline & deputy department head & 19 & 9.4 \\
\hline & department head & 7 & 3.4 \\
\hline \multirow{2}{*}{ Position } & partner & 180 & 88.7 \\
\hline & manager & 23 & 11.3 \\
\hline \multirow{3}{*}{ Sector } & clinic & 36 & 17.7 \\
\hline & semi-hospital & 88 & 43.3 \\
\hline & hospital & 79 & 38.9 \\
\hline \multirow{2}{*}{ Company } & domestic & 189 & 93.1 \\
\hline & international & 14 & 6.9 \\
\hline Total & & 203 & 100.0 \\
\hline
\end{tabular}

2. 신뢰성 및 탐색적 요인분석

본 연구에서 제안한 가설들을 검증하기 위해 측 정도구의 신뢰성과 타당성을 검증하였다. <Table 2>와 <Table 3>에서 제시된 모든 연구변수의 크론 바하 알파계수는 0.6 이상으로 신뢰성이 양호한 것 으로 나타났다. 측정도구의 요인분석은 보편적으로 활용하고 있는 요인추출방법으로 주성분분석을 통 한 베리맥스 직각회전을 이용하였다. <Table 2>와 <Table 3>에서 보는바와 같이 탐색적 요인분석을 통하여 고유치가 1 이상인 7 개의 요인이 탐색되었 으며, 내부마케팅 구성요소인 4 개 요인의 누적된
설명 분산은 $87.042 \%$ 를 설명하는 요인으로 나타났 다. 종속변수의 3 개 요인의 누적된 설명 분산은 $78.715 \%$ 를 설명하는 요인으로 나타났다. 일반적으 로 신뢰도 분석은 0.6 이상이면 신뢰성이 있다고 판 단되며 요인별 문항은 모두 0.6 이상으로 나타나 내 적일관성이 확보되었다. <Table 2>와 <Table 3>은 연구변수들에 대한 탐색적 요인분석을 실시한 결 과이다. 
The Relationship among Internal Marketing Activities, Job Satisfaction, Organizational Commitment, and Turnover Intention in Pharmaceutical Companies -Focusing on pharmaceutical salespeople-

$<$ Table 2> Factor loadings for internal marketing

\begin{tabular}{|c|c|c|c|c|c|c|}
\hline Construct concept & Item & Factor1 & Factor2 & Factor3 & Factor4 & Cronbach $a$ \\
\hline \multirow{3}{*}{$\begin{array}{l}\text { delegation } \\
\text { of } \\
\text { authority }\end{array}$} & delegation of authority 1 & .883 & 200 & 125 & .196 & \multirow{3}{*}{0.919} \\
\hline & delegation of authority2 & .871 & 170 & 212 & .177 & \\
\hline & delegation of authority 3 & .857 & .190 & .218 & .187 & \\
\hline \multirow{3}{*}{ reward system } & reward system1 & .218 & .872 & .241 & .246 & \multirow{3}{*}{0.941} \\
\hline & reward system2 & 230 & 852 & .283 & .263 & \\
\hline & reward system3 & .189 & .811 & .245 & .283 & \\
\hline \multirow{3}{*}{$\begin{array}{l}\text { education } \\
\text { \& training }\end{array}$} & education \& training1 & 176 & 236 & .850 & .230 & \multirow{3}{*}{0.910} \\
\hline & education \& training2 & 236 & 193 & .847 & .205 & \\
\hline & education \& training3 & .168 & .285 & .828 & .198 & \\
\hline \multirow{3}{*}{ internal communication } & internal communication1 & .210 & 221 & 207 & .871 & \multirow{3}{*}{0.922} \\
\hline & internal communication2 & .188 & 241 & 194 & .870 & \\
\hline & internal communication3 & 219 & 316 & .272 & .783 & \\
\hline \multicolumn{2}{|l|}{ Eigenvalue } & 6.814 & 1.440 & 1.185 & 1.006 & \\
\hline \multicolumn{2}{|c|}{ Percentage of varience explained } & 56.787 & 11.998 & 9.871 & 8.385 & \\
\hline \multicolumn{2}{|c|}{ Percentage of accumulate varience explained } & 56.787 & 68.786 & 78.657 & 87.042 & \\
\hline
\end{tabular}

$<$ Table 3> Factor loadings for dependent variables

\begin{tabular}{|c|c|c|c|c|c|}
\hline construct concept & item & Factor1 & Factor2 & Factor3 & Cronbach a \\
\hline \multirow{5}{*}{ turnover intention } & turnover intention1 & .888 & -.129 & -.166 & \multirow{5}{*}{0.924} \\
\hline & turnover intention2 & .880 & -.118 & -.110 & \\
\hline & turnover intention3 & .855 & -.057 & -.121 & \\
\hline & turnover intention4 & .828 & -.194 & -.214 & \\
\hline & turnover intention5 & .805 & -.233 & -.117 & \\
\hline \multirow{4}{*}{$\begin{array}{l}\text { organizational } \\
\text { commitment }\end{array}$} & organizational commitment1 & -.175 & .913 & .203 & \multirow{4}{*}{0.944} \\
\hline & organizational commitment2 & -.146 & .899 & .201 & \\
\hline & organizational commitment3 & -.169 & .872 & .216 & \\
\hline & organizational commitment4 & -.182 & .838 & .304 & \\
\hline \multirow{4}{*}{ job satisfaction } & job satisfaction1 & -.197 & .141 & .874 & \multirow{4}{*}{0.869} \\
\hline & job satisfaction2 & -.198 & .201 & .866 & \\
\hline & job satisfaction3 & -.173 & .228 & .798 & \\
\hline & job satisfaction4 & -.054 & .377 & 643 & \\
\hline \multicolumn{2}{|l|}{ Eigenvalue } & 6.274 & 2.448 & 1.511 & \\
\hline \multicolumn{2}{|c|}{ Percentage of varience explained } & 48.261 & 18.832 & 11.621 & \\
\hline \multicolumn{2}{|c|}{ Percentage of accumulate varience explained } & 48.261 & 67.094 & 78.715 & \\
\hline
\end{tabular}

\section{3. 확인적 요인분석}

탐색적 요인분석에 이어서 $\mathrm{AMOS} 20.0$ 을 이용 하여 확인적 요인분석을 실시하였다. 확인적 요인 분석 결과는 <Table $4>$ 와 같다. 대부분의 지표 값 들은 $\mathrm{X}^{2}=279.870, \mathrm{~d} . \mathrm{f}=230, \mathrm{p}=0.014, \mathrm{GFI}=0.902$, AGFI=0.861, NFI=0.943, CFI=0.989, RMR=0.087으
로 적합도 평가기준을 충족시키는 것으로 나타나 측정모형의 적합도는 수용할만한 수준이라 할 수 있다.

복합신뢰도(Composite Reliability:CR)와 평균분 산추출값(Average Variance Extracted:AVE)은 Bagozzi와 Yi[16]가 제시한 기준(각각 0.7이상, 0.5 이상)보다 높게 나타났으며, 측정항목들과 구성개 
념들을 연결하는 표준화 요인적재치가 통계적으로 95\% 신뢰구간에서 유의적이기 때문에 집중타당성 이 입증되었다. 또한 단일차원성이 입증된 각 요인 들 사이의 판별타당성의 충족정도와 요인 간의 관 계의 방향과 정도를 확인하기 위하여 각 요인들
간의 상관관계를 <Table $5>$ 과 같이 분석하였다. 상관관계 분석결과 각 요인간의 관계가 가설에서 설정한 바와 같은 방향으로 나타나 있고 서로 간 의 상관계수가 1 인 관계가 나타나지 않아 판별타 당성과 기준타당성이 충족된다고 할 수 있다.

\section{$<$ Table 4> Result of CFA}

\begin{tabular}{|c|c|c|c|c|c|c|c|}
\hline construct concept & Item & $\begin{array}{c}\text { factor } \\
\text { loading }\end{array}$ & $\begin{array}{c}\text { Standardized } \\
\text { factor loading }\end{array}$ & S.E & t value & $\mathrm{CR}$ & AVE \\
\hline \multirow{3}{*}{$\begin{array}{l}\text { delegation of } \\
\text { authority }\end{array}$} & delegation of authority1 & 1 & 0.889 & - & - & \multirow{3}{*}{0.83} & \multirow{3}{*}{0.62} \\
\hline & delegation of authority2 & 0.876 & 0.814 & 0.068 & 12.85 & & \\
\hline & delegation of authority3 & 1.013 & 0.881 & 0.078 & 12.959 & & \\
\hline \multirow{3}{*}{ reward system } & reward system1 & 1 & 0.879 & - & - & \multirow{3}{*}{0.85} & \multirow{3}{*}{0.65} \\
\hline & reward system2 & 1.028 & 0.935 & 0.066 & 15.518 & & \\
\hline & reward system3 & 0.988 & 0.905 & 0.066 & 14.883 & & \\
\hline \multirow{3}{*}{$\begin{array}{l}\text { education } \\
\text { \& training }\end{array}$} & education \& training1 & 1 & 0.874 & - & - & \multirow{3}{*}{0.84} & \multirow{3}{*}{0.63} \\
\hline & education\& training2 & 1.061 & 0.879 & 0.08 & 13.266 & & \\
\hline & education\& training3 & 1.009 & 0.863 & 0.081 & 12.506 & & \\
\hline \multirow{3}{*}{ internal communication } & internal communication1 & 1 & 0.932 & - & - & \multirow{3}{*}{0.83} & \multirow{3}{*}{0.62} \\
\hline & internal communication2 & 0.896 & 0.799 & 0.064 & 14.068 & & \\
\hline & internal communication3 & 0.82 & 0.852 & 0.053 & 15.412 & & \\
\hline \multirow{4}{*}{ job satisfaction } & job satisfaction1 & 1 & 0.737 & - & - & \multirow{4}{*}{0.84} & \multirow{4}{*}{0.57} \\
\hline & job satisfaction2 & 0.917 & 0.718 & 0.085 & 10.747 & & \\
\hline & job satisfaction3 & 1.128 & 0.72 & 0.106 & 10.679 & & \\
\hline & job satisfaction4 & 1.27 & 0.797 & 0.119 & 10.695 & & \\
\hline \multirow{4}{*}{$\begin{array}{l}\text { organizational } \\
\text { commitment }\end{array}$} & $\begin{array}{l}\text { organizational } \\
\text { commitment1 }\end{array}$ & 1 & 0.935 & - & - & \multirow{4}{*}{0.88} & \multirow{4}{*}{0.66} \\
\hline & $\begin{array}{l}\text { organizational } \\
\text { commitment2 }\end{array}$ & 1.014 & 0.931 & 0.055 & 18.285 & & \\
\hline & $\begin{array}{l}\text { organizational } \\
\text { commitment3 }\end{array}$ & 0.952 & 0.874 & 0.065 & 14.552 & & \\
\hline & $\begin{array}{l}\text { organizational } \\
\text { commitment4 }\end{array}$ & 0.908 & 0.831 & 0.066 & 13.783 & & \\
\hline \multirow{5}{*}{ turnover intention } & turnover intention1 & 1 & 0.807 & - & - & \multirow{5}{*}{0.88} & \multirow{5}{*}{0.59} \\
\hline & turnover intention2 & 0.985 & 0.8 & 0.069 & 14.275 & & \\
\hline & turnover intention3 & 1.253 & 0.967 & 0.095 & 13.255 & & \\
\hline & turnover intention4 & 1.125 & 0.865 & 0.091 & 12.361 & & \\
\hline & turnover intention5 & 0.956 & 0.735 & 0.07 & 13.661 & & \\
\hline
\end{tabular}


The Relationship among Internal Marketing Activities, Job Satisfaction, Organizational Commitment, and Turnover Intention in Pharmaceutical Companies -Focusing on pharmaceutical salespeople-

$<$ Table 5> Correlation result

\begin{tabular}{|c|c|c|c|c|c|c|c|}
\hline & DA & ET & RS & IC & JS & OC & $\mathrm{TI}$ \\
\hline Delegation of Authority & 1 & & & & & & \\
\hline Education \& Training & $.478 * *$ & 1 & & & & & \\
\hline Reward System & $.500 * *$ & $.589 * *$ & 1 & & & & \\
\hline Internal Communication & $.492 \star \star$ & $.545 * \star$ & $.615 * \star$ & 1 & & & \\
\hline Job Satisfaction & $.578 * *$ & $.478 * *$ & $.594 * *$ & $.618 * *$ & 1 & & \\
\hline Organizational Commitment & $.312 * *$ & $.335 * *$ & $.400 * *$ & $.437 * *$ & $.522 * *$ & 1 & \\
\hline Turnover Intention & $-.207 * \star$ & $-.141 *$ & $-.212 \star \star$ & $-.237 \star \star$ & $-.386 * \star$ & $-.375 * \star$ & 1 \\
\hline
\end{tabular}

$* * * p<0.01, * * p<0.05, * p<0.1$

\section{4. 모형검증 및 가설검정}

모형을 통하여 가설을 검증한 결과 15 개 가설 중 5 개의 가설이 채택되었다. 전체 가설검정 결과 는 <Table 6>에 제시하였다. 본 논문의 연구모형 을 검증하기 위하여 $\mathrm{AMOS} 20.0$ 을 이용하여 경로 분석을 실시하였다<Figure 2>. 전체 구조모형 적 합도 검증결과 적합통계량과 적합지수들이 $\mathrm{X}^{2}$ $=186.753, \quad$ d.f $=215, \quad \mathrm{p}=0.918, \quad \mathrm{GFI}=0.932$, $\mathrm{AGFI}=0.897, \mathrm{NFI}=0.962, \mathrm{CFI}=1.000, \mathrm{RMR}=0.076$ 로 나타났다. 일부 적합도 지수가 충족되지 못하고 있 으나 GFI, NFI, CFI등 대부분의 주요 적합도 지수 가 기준을 충족하고 있으므로 전반적으로 모형이 적합함을 시사하고 있다. 모형에서 먼저 내부마케 팅활동 요인과 직무만족의 인과관계 검증결과, 내 부커뮤니케이션 $(\mathrm{t}=4.672, \mathrm{p}<0.01)$, 권한위임 $(\mathrm{t}=4.988$, $\mathrm{p}<0.01)$, 보상제도 $(\mathrm{t}=2.086, \mathrm{p}<0.05)$ 순으로 긍정적 인 영향을 미치며 교육훈련은 유의한 영향을 미치 지 않았다. 다음으로 내부마케팅활동 요인과 조직 몰입, 이직의도와의 인과관계 검증결과, 내부마케 팅활동 요인은 조직몰입, 이직의도에 유의한 영향 을 미치지 않았다. 직무만족과 조직몰입의 인과관 계 검증결과에서는 긍정적인 영향을 미치는 것으 로 나타났다 $(\mathrm{t}=3.653, \mathrm{p}<0.01)$. 직무만족과 이직의도 의 인과관계 검증결과에서는 부정적인 영향을 미
치는 것으로 나타났다 $(\mathrm{t}=-2.372, \mathrm{p}<0.01)$. 그러나 조 직몰입과 이직의도의 인과관계에서는 검증결과 유 의한 영향을 미치지 않았다(t=-1.159, $\mathrm{p}=0.247)$. 연 구모형의 표준화된 총 효과, 직접효과 및 간접효과 와 다중상관자승(Squared multiple correlations, $\mathrm{SMC}$ )값은 <Table 7>과 같다. 내부마케팅활동 요 인은 조직몰입 및 이직의도에 유의한 영향을 미치 지 못하였다. 그러나 내부마케팅활동 요인 중 권한 위임과 내부커뮤니케이션, 보상제도는 조직몰입에 정(+)의 간접적인 영향을 미쳤다. 또한 권한위임과 내부커뮤니케이션요인은 이직의도에 부(-)의 간접 적인 영향을 미쳤다. 즉 내부마케팅 활동 중 권한 위임과 내부커뮤니케이션, 보상제도가 높을수록 직 무만족이 높아지게 되고 조직몰입도 높아진다는 것이다. 그리고 내부마케팅 활동 중 권한위임과 내 부커뮤니케이션 활동이 높을수록 이직의도가 낮아 진다는 것을 간접적인 영향관계로 확인할 수 있었 다. 직무만족의 $\mathrm{SMC}$ 값은 0.754 로 나타났으며 조직 몰입의 $\mathrm{SMC}$ 값은 0.414 , 이직의도의 $\mathrm{SMC}$ 값은 0.227 로 나타났다. 
The Korean Journal of Health Service Management Vol.7 No.1 (March 2013)

$<$ Table 6> Result of Path analysis

\begin{tabular}{|c|c|c|c|c|c|c|c|c|}
\hline Hypothesis & Path diagram & $\begin{array}{l}\text { Hypothesis } \\
\text { direction }\end{array}$ & $\begin{array}{l}\text { standized } \\
\text { regression } \\
\text { weights }\end{array}$ & $\begin{array}{l}\text { regression } \\
\text { weights }\end{array}$ & S.E & t-value & $P$ value & support \\
\hline 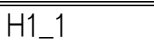 & $\overline{D D A}->\mathrm{JS}$ & + & 0.424 & 0.397 & 0.080 & 4.988 & 0.000 & support \\
\hline H1_2 & $E T \rightarrow>J S$ & + & -0.068 & -0.071 & 0.092 & -0.768 & 0.443 & reject \\
\hline H1_3 & RS $->J S$ & + & 0.203 & 0.200 & 0.096 & 2.086 & 0.037 & support \\
\hline H1_4 & $I C \rightarrow>J S$ & + & 0.439 & 0.402 & 0.086 & 4.672 & 0.000 & support \\
\hline H2_1 & $D A->O C$ & + & -0.326 & -0.347 & 0.143 & -2.421 & 0.015 & reject \\
\hline $\mathrm{H} 2 \_2$ & $E T->O C$ & + & 0.097 & 0.115 & 0.124 & 0.932 & 0.351 & reject \\
\hline H2_3 & $\mathrm{RS}->\mathrm{OC}$ & + & 0.028 & 0.031 & 0.132 & 0.238 & 0.812 & reject \\
\hline H2_4 & $\mid C->O C$ & + & -0.061 & -0.064 & 0.156 & -0.408 & 0.683 & reject \\
\hline H3_1 & $\mathrm{DA} \rightarrow \mathrm{TI}$ & - & 0.145 & 0.162 & 0.167 & 0.973 & 0.331 & reject \\
\hline H3_2 & $E T \rightarrow T I$ & - & 0.056 & 0.070 & 0.135 & 0.520 & 0.603 & reject \\
\hline H3_3 & $\mathrm{RS}->\mathrm{TI}$ & - & 0.114 & 0.134 & 0.145 & 0.926 & 0.354 & reject \\
\hline H3_4 & $|C->T|$ & - & 0.079 & 0.087 & 0.161 & 0.541 & 0.589 & reject \\
\hline $\mathrm{H} 4$ & $J S->O C$ & + & 0.822 & 0.934 & 0.256 & 3.653 & 0.000 & support \\
\hline H5 & $\mathrm{JS}->\mathrm{TI}$ & - & -0.630 & -0.756 & 0.319 & -2.372 & 0.018 & support \\
\hline $\mathrm{H} 6$ & $\mathrm{OC}->\mathrm{TI}$ & - & -0.123 & -0.13 & 0.112 & -1.159 & 0.247 & reject \\
\hline
\end{tabular}

$\star * \star p<0.01, \quad * \star p<0.05, * p<0.1$

$<$ Table 7> Standardized Total Effects, Direct Effects, Indirect Effects

\begin{tabular}{lccccccc}
\hline & \multicolumn{3}{c}{ Organizational Commitment } & \multicolumn{4}{c}{ Turnover Intention } \\
\cline { 2 - 8 } & $\begin{array}{c}\text { Total } \\
\text { Effects }\end{array}$ & $\begin{array}{c}\text { Direct } \\
\text { Effects }\end{array}$ & $\begin{array}{c}\text { Indirect } \\
\text { Effects }\end{array}$ & $\begin{array}{c}\text { Total } \\
\text { Effects }\end{array}$ & $\begin{array}{c}\text { Direct } \\
\text { Effects }\end{array}$ & $\begin{array}{c}\text { Indirect } \\
\text { Effects }\end{array}$ & SMC \\
\hline \hline Delegation of Authority & 0.022 & -0.326 & $0.348 * * *$ & -0.125 & 0.145 & $-0.152 * *$ & - \\
Education \& Training & 0.042 & 0.097 & -0.056 & 0.094 & 0.056 & 0.038 & - \\
Reward System & 0.195 & 0.028 & $0.167 *$ & -0.380 & 0.114 & -0.152 & - \\
Internal Communication & 0.299 & -0.061 & $0.361 * * *$ & -0.234 & 0.079 & $-0.313 * * *$ & - \\
Job Satisfaction & 0.822 & 0.822 & - & -0.731 & -0.630 & -0.101 & 0.754 \\
Organizational Commitment & - & - & - & -0.123 & -0.123 & - & 0.414 \\
Turnover Intention & - & - & - & - & - & - & 0.227 \\
\hline
\end{tabular}

$* * * p<0.01, * * p<0.05, * p<0.1$

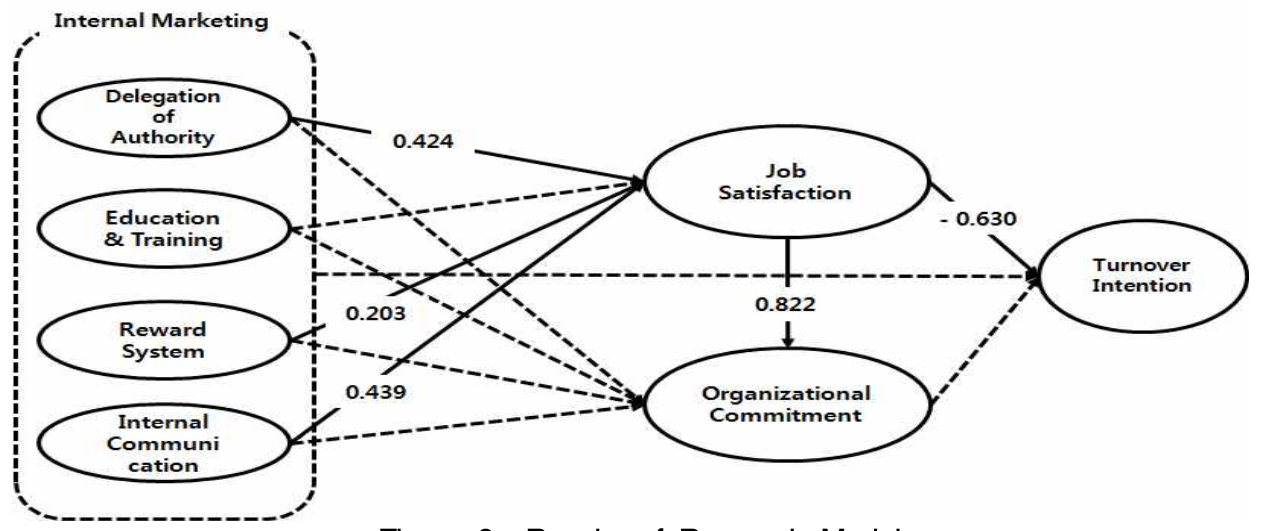

$<$ Figure 2> Results of Research Model 


\section{$\mathrm{IV}$. 고찰 및 결론}

본 연구에서는 제약회사의 내부마케팅활동(권한 위임, 교육훈련, 보상제도, 내부커뮤니케이션)과 직 무만족, 직무몰입, 이직의도와의 관계를 알아보고 자 제약영업사원들을 대상으로 살펴보았다. 실증적 연구결과는 다음과 같이 요약해 볼 수 있다.

첫째, 가설 1 에서 제시한 내부마케팅활동 요인 과 직무만족 간의 인과관계를 살펴본 결과 내부커 뮤니케이션, 권한위임, 보상제도가 직무만족에 긍 정적인 영향을 주는 것으로 나타났다. 반면, 교육 훈련은 직무만족에 긍정적인 영향을 주지 않는 것 으로 나타났다. 이러한 결과는 제약영업사원들에게 업무수행에 도움을 주는 것은 내부커뮤니케이션이 잘 통하고 영업사원들에게 권한을 위임하여 책임 감을 부여하며 그에 따른 보상을 적절히 해주는 것이 직무만족을 향상시킨다는 것을 알 수 있다. 반면에 교육훈련이 너무 잦으면 업무에 방해가 될 수 있으므로 직무만족에는 유의한 영향을 미치지 않은 것으로 사료된다. 기존 연구에서는 역할 명 확, 보상제도, 근무환경, 훈련이나 상사의 관심 및 공정한 행정에 해당하는 경영평가의 5 가지 요인에 서 보상제도를 제외한 나머지가 직무만족에 유의 한 영향을 미치고 경영평가요인이 가장 많은 영향 력을 미쳤다[17]. 그리고 Ahmed와 Rafiq[18]의 연 구에서는 권한위임, 기능 간 상호협조와 통제, 마 케팅과 유사한 접근, 종사원의 동기부여의 네 가지 요인과 직무만족과의 관계에서 동기부여와 권한위 임이 직무만족에 유의한 영향을 미쳤다. 또한 호텔 식음료 부서장의 내부마케팅 활동이 구성원의 자 기효능감, 직무만족에 미치는 연구에서 임파워먼 트, 보상제도, 교육훈련을 제시하였는데 모든 요인 이 직무만족에 유의한 영향을 미쳤다[19]. 둘째, 가 설 2에서 제시한 내부마케팅활동 요인과 조직몰입 간의 인과관계를 살펴본 결과 내부마케팅활동 요 인은 조직몰입에 유의한 영향을 미치지 않는 것으
로 나타났다. 선행연구에서는 보상제도를 제외한 근무환경 및 휴가제도, 교육훈련, 종사원의 의견수 렴, 커뮤니케이션 및 역할명확성, 임파워먼트의 요 인들이 긍정적인 영향을 미친다고 하였다[20]. 또 한 병원간호조직을 대상으로 내부마케팅요인과 간 호사의 조직몰입간의 상관관계에 대한 연구결과, 두 변수 간에는 높은 상관관계가 존재한다고 입증 하였다[21]. 내부마케팅활동과 조직몰입과의 상관 관계가 존재하는 것은 본 연구결과와 유사하다 그 러나 인과관계에 있어서는 직접적으로 유의한 영 향을 미치지 못하였다. 그러나 권한위임, 보상제도, 내부커뮤니케이션은 간접적으로 정(+)의 유의한 영 향을 미쳤다. 이는 아직 제약회사에서는 영업사원 들에게 있어 내부마케팅활동이 조직차원에서 종사 원의 욕구를 만족시킬 정도로 그들의 행동에 대한 피드백과 보상을 시행하지 못하고 있다는 것이다. 또한 영업부서를 통해 기술훈련과 지식훈련을 제 공함에 있어 조직 내에서 구성원과의 커뮤니케이 션, 구성원 불평불만 처리과정 및 종사원의 욕구를 명확히 인식하지 못하고 있는 것으로 판단된다. 셋 째, 가설 3에서 제시한 내부마케팅활동 요인과 이 직의도 간의 인과관계를 살펴본 결과 내부마케팅 활동 요인은 이직의도에 직접적으로 유의한 영향 을 미치지 않았다. 그러나 권한위임과 내부커뮤니 케이션은 부(-)의 간접적인 영향을 미쳤다. 이는 권 한위임과 내부커뮤니케이션이 높을수록 직무만족 이 높아지고 이직의도가 낮아진다는 것이다. 가설 4 에서 가설 6 까지의 직무만족, 조직몰입, 이직의도 의 인과관계에서는 직무만족은 조직몰입에 정 $(+)$ 의 영향을 미치며 직무만족은 이직의도에 부(-)의 영 향을 미쳤다. 조직몰입은 이직의도에 통계적으로 유의한 영향을 미치지 않았으나 부(-)의 영향을 미 쳤다. 이는 선행연구와 비슷한 결과이다[22][23]. 이 러한 연구결과는 제약회사의 내부고객인 영업사원 들에게 직무만족은 조직몰입을 향상시키고 직무만 족이 높을수록 이직의도를 감소시킬 수 있다는 시 
사점을 제공하고 있다. 이는 권한위임이나 보상제 도, 내부커뮤니케이션을 통한 내부마케팅활동이 영 업사원을 만족시키는 경우에 다른 회사나 다른 부 서 또는 다른 산업으로 옮길 의향이 적은 것으로 나타났다.

본 연구의 실증분석 결과를 토대로 제약회사에 있어서 내부마케팅에 대한 몇 가지 실무적인 시사 점을 제시하고자 한다. 첫째, 내부마케팅 요인 중 에서 내부커뮤니케이션이 직무만족에 가장 큰 유 의한 영향을 주는 것으로 나타났으며 교육훈련은 유의하지 않은 결과로 나타났다. 이는 영업사원들 이 영업본부와의 내부커뮤니케이션 활동이 활발하 게 이루어지는 경우에 직무만족이 높게 나타난다 는 것을 알 수 있다. 따라서 제약회사의 영업본부 는 영업사원들과 소통할 수 있는 다양한 루트를 개발하고 영업사원들의 의견을 충분히 수렴하여 효과적인 영업 전략을 세울 필요가 있다. 예를 들 어 업무나 고객관련, 창의적인 아이디어 등의 정보 제공을 위한 이메일이나 핫라인 등을 개발하거나 지속적인 관리를 하고 영업사원들의 불편, 불만, 건의사항 등을 관리해 주는 전담부서나 지원시스 템을 구축할 필요가 있을 것이다. 둘째, 내부마케 팅 요인 중 권한 위임이 직무만족에 정(+) 영향을 주는 것으로 나타났다. 주로 고객을 상대하는 영업 사원들은 대고객과의 관계에서 업무처리에 대한 결정권을 많이 부여해 줄 때 자신의 업무에 자신 감을 가지며, 고객에 대한 문제가 발생하였을 때 자신의 판단 하에 문제를 해결할 수 있도록 허용 해 줄 때 책임감을 가지게 된다[24]. 직장상사의 지원은 직무와 관련하여 상사와의 우호적인 관계 를 맺으며 능력과 경쟁이 강조되는 사회분위기 속 에서 상사의 지원으로 근로자들은 더욱 더 조직에 긍정적인 태도를 보일 수 있다[25]. 따라서 제약회 사는 경영층이나 임원들에게만 권한을 집중시키지 말고 현장에서 실질적으로 고객들을 대상으로 업 무를 처리하는 영업사원들이 신속하고 정확한 의
사결정을 할 수 있도록 권한위임을 제공할 필요가 있다. 셋째, 제약회사에서는 전략적인 측면에서 영 업사원을 내부고객으로 인식하고 내부마케팅활동 이 원활하게 이루어진다면 영업사원들의 직무만족 이 향상되고 조직에 더 몰입할 수 있으며 이직을 줄일 수 있을 것이다. 이직이 발생하게 되면 새로 운 인적자원을 채용하기 위해 일정한 시간과 노력 이 필요하기 때문에 비용문제가 발생한다. 이러한 시간과 노력에는 기존의 구성원이 개입되며 이에 따른 부담을 비용으로 환산할 경우 이직에 따른 손실은 적지 않다. 이직관리가 효과적으로 이루어 진다면 기업의 입장에서 그에 따른 비용부담을 줄 일 수 있을 것이다. 인적자원의 중요성은 많은 연 구를 통해서 제시되었고 그중에서도 영업사원은 실제적으로 서비스를 제공하는 주체이기 때문에 관리가 상당히 중요하다. 이들의 만족과 조직에 대 한 애착은 고객에게 제공되는 서비스품질과 직결 되기 때문에 효과적으로 관리한다면 경쟁력을 증 진시킬 수 있을 것이다. 따라서 제약회사의 경영층 은 내부고객지향적인 경영자가 되어 현장의 접점 에서 활동 중인 영업사원들의 옥구를 실질적으로 파악하여 개선시키도록 노력해야 할 것이다. 경영 본부에서는 내부커뮤니케이션을 활성화하여 현장 의 목소리를 수렴하고 수직적인 조직체계가 아닌 수평적인 파트너십으로 권한을 일부 위임하고 그 에 따른 책임감을 부여할 필요가 있다. 또한 성과 에 따른 보상이 적절히 시행된다면 영업사원들은 보다 안정적인 근무환경에서 기업성과를 최대화하 도록 노력할 것이다.

본 연구의 한계점은 첫째, 다양한 내부마케팅활 동 요인들 중에서 본 연구에서 제시된 요인 외에 다양한 요인들에 대해서는 함께 다루지 못하였다. 더 많은 내부마케팅 요인을 추가하여 분석할 필요 가 있다. 둘째, 표본 중에서 국내제약회사의 비중 이 외국계제약회사의 비중보다 상대적으로 많고 여성보다 남성의 비율이 다소 높았기 때문에 일반 
The Relationship among Internal Marketing Activities, Job Satisfaction, Organizational Commitment, and Turnover Intention in Pharmaceutical Companies -Focusing on pharmaceutical salespeople-

화하기에는 어렵다. 셋째, 아직까지 영업사원과 관 련된 국내 연구가 미비하다. 따라서 좀 더 추가적 인 연구가 필요하다고 판단된다. 향후 연구에서는 제약영업사원과 관련된 다양한 연구를 통해 인적 자원의 중요성을 제고하고 내부마케팅 요인과 판 매실적 및 매출자료 등의 계량적인 결과 값을 적 용하여 실질적으로 기업성과나 조직성과에 어떠한 영향을 미치는가를 추가 연구할 필요가 있다.

\section{REFERENCES}

1. N. Bendapudi, Robert P., Leone(2002), Managing Business-to-Business Customer Relationship Following Key Contact Employee Turnover in a Vendor Firm, Journal of Marketing, Vol.66(April);83-101.

2. Cannon, J.P., Perrault, W.D. Jr.(1999), Buyer-seller relationship in business market, Journal of Marketing Research, Vol.36;439-460.

3. S.P. Brown, R.A. Peterson(1994), The effect of effort on sales performance and job satisfaction, Journal of Marketing, Vol.58(2);70-80.

4. Anderson, Eugene, Thomas, S. Robertson(1995), Inducing Multiline Salespeople to Adopt House Brands, Journal of Marketing, Vol.59(April);16-31.

5. K.H. Jeon, J.W. Kim, S.R. Mo(2003), A Study on Antecedents of Salesforce Turnover Intention: Relationship Theory Perspective, Korea Marketing Review, Vol.18(2);95-122.

6. K.H. Jeon, S.Y. Kim(2004), The Role of Alternative Attractiveness in the Relationships among Job Performance, Satisfaction, Organizational Commitment, and Turnover Intention, Journal of Distribution Research, Vol.9(2);45-73.

7. N.S. Yoon, Y.J. Lee, M.H. Son(2008), The Effect of Internal Marketing on Job Attitude and
Customer rientation in Casino Industry: The Case of Casino in Seoul, Korea Journal of Tourism and Hospitality Research, Vol.22(2);317-334.

8. K.H. Chung(2005), The Effect of Internal Marketing and Organizational Dynamics on Market Orientation, Korean Corporation Management Review, Vol.20(1);1-22.

9. J.R. Hauser, D.I. Simester, B. Wemerfelt(1996), Internal Customer and Internal Supplier, Journal of Marketing Research, Vol.33(3);268-280.

10. M. Rafiq, P.K. Ahmed(2000), A Meta-Model of Internal Marketing, in Internal Marketing: Direction for Management, ed: R. Varey and B. Lewis, Routledge Press, London, pp.223-238.

11. M.P. Singh(2000), A Social Semantics for Agent Communication Languages, In Proceedings of the IJCAI Workshop on Agent Communication Languages, Springer, pp.31-45.

12. E.A. Locke(1976), The nature and causes of job satisfaction, in Dunnette, M.(Ed), Handbook of Industrial and Organizational Psychology, Rand McNally, Chicago. IL, pp.1297-1350.

13. A.H. Brayfield, H.F. Rothe(1951), An index of job satisfaction, Journal of Applied Psychology, Vol.35(5);307-311.

14. N.J. Allen, J.P. Meyer(1990), The measurement and antecedents of affective, continuance, and normative commitment to the organization, Journal of Occupational Psychology, Vol.63;1-8.

15. C.E. Michael, P.E. Specter(1982), Cause of Employee Turnover: A Test of the Mobley, Griffeth, Hand \& Meglino model, Journal of Applied Psychology, Vol.67;53-59.

16. R.P. Bagozzi, Y. Yi(1988), On the evaluation of structural equation models, Journal of the Academy Marketing Science, Vol.16(1);74-94.

17. D.B. Arnett, D.A. Laverie, C. McLane(2002), 
Using Job Satisfaction and Pride as Internal Marketing Tools, Cornell Hotel and Restaurant Administration Quarterly, Vol.1(1);87-96.

18. P.K. Ahmed, M. Rafiq(2000), Advances in the Internal Marketing Concept: Definition, Synthesis and Extension, Journal of Services Marketing, Vol.14(6);449-462.

19. K.M. Lee, G.T. Lee, B.H. Song(2012), A Study on Effect of Internal Marketing Activities of Hotel F\&B Department Head on the Self-efficacy and Job Satisfaction, Journal of Hotel \& Resort, Vol.11(1);179-197.

20. J.S. Han, E.J. Kim(2005), The Effect of Internal Marketing Activities on Job Satisfaction, Organizational Commitment, and Customer Orientation in the Hotel Industry, Korean Journal of Hotel Administration, Vol.14(3);191-213.

21. S.I. Kim, S.K. Cha, J.Y. Lim(2001), A Correlational Study among Internal Marketing Factor, Nurses Job Satisfaction, and Organizational Commitment in Hospital Nursing Organization, Journal of Korean Public Health Nursing, Vol.15(1);42-55.

22. J.M. Cho(2009), Effects of Job Environment of the PCO on Organizational Commitment and Intention of Turnover, International journal of interpretation and translation, Vol.9(3);101-123.

23. H.S. Lee, J.W. Kim, S.H. Kim and S.K. Hwang(2012), The Effect of Worker's Job Satisfaction and Turnover Intention of Hospital Welfare, The Korean Journal of Health Service Management, Vol.6(3);107-115.

24. H.S. Shin(2000), Impacts of Internal Marketing on the employees' Organizational Identification in Hotels, Journal of Tourism Science, Vol.22(1);149-164.

25. J.Y. Oh, Y.J. Seo, H.S. Park(2012), Determinants of Intent to Leave among Workers at Long-Term Care Institutions, The Korean Journal of Health Service Management, Vol.6(1);87-103.

접수일자 2013년 1월 16일 심사일자 2013년 1월 17일 게재확정일자 2013년 2월 8일 